DISTRIBUTION STATEMENT A. Approved for public release; distribution is unlimited.

\title{
Optimized Infrastructure for the Earth System Prediction Capability
}

\author{
PI: Cecelia DeLuca \\ 325 Broadway \\ Boulder, CO 80305 \\ phone: (303) 497-3604 email: Cecelia.Deluca@noaa.gov \\ Award Number: N00014-13-1-0508 \\ http://www.earthsystemcog.org/projects/espc-infrastructure/
}

\section{LONG-TERM GOALS}

Note: This project ends on October 31, 2014. Ongoing work will be reported through the project $A n$ Integration and Evaluation Framework for ESPC Coupled Models (PI Kirtman).

The Earth System Prediction Capability (ESPC) interagency program was established in 2010 as an effort to improve collaboration across the federally sponsored environmental research and operational prediction communities. The ESPC goal is to coordinate scientific development and operational implementation of improved global prediction at the weather to climate interface. Part of the ESPC role is to advocate for and support the basic foundations of modeling and data systems, such as the computational efficiency of models and common coupled system architectures.

The Optimized Infrastructure for ESPC (OI for ESPC) project is working to advance the computational foundations of ESPC through three integrative activities. These activities are designed to leverage numerical libraries across agencies; to explore the impacts of emerging computing platforms on coupled model infrastructure; and to reconcile conventions across different model architectures. The activities are serving as a starting point for a broader effort funded through the 2013 NOPP program Advancing Air-Ocean-Land-Ice Global Coupled Prediction on Emerging Computational Architectures (AOLI).

\section{OBJECTIVES}

1. Update Numerical Libraries in ESMF. The Earth System Modeling Framework (ESMF) is widely used in the ESPC community for building and coupling models. We will adapt $\mathrm{MOAB}$, a finite element mesh package in active development at the University of Wisconsin and Argonne National Laboratory, for use as an ESMF computational kernel. The intent is to evaluate MOAB as a replacement for the native ESMF implementation of finite element mesh software. The framework uses this mesh software to create a unified representation of structured and unstructured grids, and define operations that work across grid types. The desired outcome is an immediate boost of new features in ESMF, and in the longer term, an opportunity to leverage the work that goes into ongoing functions and optimizations in MOAB and associated DOE libraries. 


\section{Report Documentation Page}

Form Approved

OMB No. 0704-0188

Public reporting burden for the collection of information is estimated to average 1 hour per response, including the time for reviewing instructions, searching existing data sources, gathering and maintaining the data needed, and completing and reviewing the collection of information. Send comments regarding this burden estimate or any other aspect of this collection of information,

including suggestions for reducing this burden, to Washington Headquarters Services, Directorate for Information Operations and Reports, 1215 Jefferson Davis Highway, Suite 1204, Arlington

VA 22202-4302. Respondents should be aware that notwithstanding any other provision of law, no person shall be subject to a penalty for failing to comply with a collection of information if it

does not display a currently valid OMB control number.

1. REPORT DATE

30 SEP 2014

4. TITLE AND SUBTITLE

Optimized Infrastructure for the Earth System Prediction Capability

6. $\operatorname{AUTHOR}(\mathrm{S})$

7. PERFORMING ORGANIZATION NAME(S) AND ADDRESS(ES)

National Oceanic and Atmospheric Administration (NOAA),325

Broadway,Boulder,CO,80305

9. SPONSORING/MONITORING AGENCY NAME(S) AND ADDRESS(ES)

3. DATES COVERED

00-00-2014 to 00-00-2014

5a. CONTRACT NUMBER

5b. GRANT NUMBER

5c. PROGRAM ELEMENT NUMBER

5d. PROJECT NUMBER

5e. TASK NUMBER

5f. WORK UNIT NUMBER

8. PERFORMING ORGANIZATION

REPORT NUMBER

10. SPONSOR/MONITOR'S ACRONYM(S)

11. SPONSOR/MONITOR'S REPORT

NUMBER(S)

12. DISTRIBUTION/AVAILABILITY STATEMENT

Approved for public release; distribution unlimited

13. SUPPLEMENTARY NOTES

14. ABSTRACT

15. SUBJECT TERMS

16. SECURITY CLASSIFICATION OF:

a. REPORT

unclassified b. ABSTRACT

unclassified c. THIS PAGE

unclassified
17. LIMITATION OF ABSTRACT

Same as

Report (SAR)
18. NUMBER 19a. NAME OF

OF PAGES RESPONSIBLE PERSON

6 
2. Optimize Component Architecture for GPUs. We will prototype a set of mechanisms that enable a component framework to optimize for accelerators, and explore how accelerators may affect mapping of components to resources. The product will be a code consisting of sample or toy components with representative operations. The intent of this research is to inform both infrastructure development and optimizations undertaken by ESPC modeling teams.

3. Couple HYCOM to CESM. We will work with developers of the HYbrid Coordinate Ocean Model (HYCOM) to couple it to the Community Earth System Model (CESM). This will enable HYCOM to be evaluated in many new coupled configurations. The activity will also define a mapping between the different coupling rules and conventions implemented in HYCOM and CESM. HYCOM uses a standard ESMF-based interface developed by a NOAA and DoD consortium (the National Unified Operational Prediction Capability, or NUOPC conventions), while CESM has its own native format based on the Model Coupling Toolkit (MCT). This is an important exercise because that mapping will apply not just to this coupling, but will provide insight into how any components that use the NOAA/DoD interface can be coupled into a CESM-based system, and vice versa.

\section{APPROACH}

Team members hold weekly telecons to discuss plans and progress. Participants include both technical and scientific team members, below:

Argonne National Laboratory/University of Chicago/University of Wisconsin: Rob Jacob, Jayesh Krishna, Tim Tautges, Jane Hu

Florida State University: Alexandra Bozec, Eric Chassignet

NCAR: Jim Edwards, Mariana Vertenstein, Tony Craig

NASA Jet Propulsion Laboratory: Peggy Li

Naval Research Laboratory: Alan.Wallcraft

University of CA San Diego: Caroline Papadopoulos, Julie McClean

University of Colorado/NOAA: Cecelia DeLuca, Kathy Saint, Gerhard Theurich, Fei Liu, Bob Oehmke, Walter Spector

University of Miami: Ben Kirtman

Above are subscribed to an espc_tech@list.woc.noaa.gov mailing list used for organizing the calls.

A website for the OI for ESPC project was created on the CoG collaboration environment: http://www.earthsystemcog.org/projects/espc-infrastructure/

Some of the OI for ESPC project activities are closely associated with a Coupling Testbed, which is a collaborative area for groups working on research problems involving model coupling. The Coupling Testbed was funded under the larger Integration and Evaluation Framework NOPP award. A site for the Coupling Testbed was also initiated and is here: http://www.earthsystemcog.org/projects/couplingtestbed/ 
Initial roadmaps were created for each of the three objectives, and are linked under the Roadmap tabs on the two sites above. The roadmaps include status at start, team members, desired outcomes, and a sequence of tasks.

\section{Update Numerical Libraries in ESMF}

http://www.earthsystemcog.org/projects/espc-infrastructure/moab_in_esmf

2. Optimize Component Architectures for GPUs

http://www.earthsystemcog.org/projects/couplingtestbed/acceleratorplans

\section{Couple HYCOM to CESM}

(Part 1) Introducing NUOPC conventions into CESM

http://www.earthsystemcog.org/projects/espc-infrastructure/nuopc_in_cesm

(Part 2) HYCOM in CESM scientific validation

http://www.earthsystemcog.org/projects/espc-infrastructure/hycom_in_cesm_science

The roadmaps are being updated by team members prior to the weekly telecons, and progress and issues are discussed during the calls. Where appropriate, test reports describing how a code base was validated are linked to the roadmaps. These test reports include information that supports the reproducibility of results.

\section{WORK COMPLETED}

The Roadmap pages listed under Approach contain detailed descriptions of the work completed. See summaries below.

\section{Update Numerical Libraries in ESMF}

In July, 2014 the MOAB team (Wilson, Tautges, $\mathrm{Hu}$ ) completed the capability to migrate a MOAB mesh to a new distribution. This is required for MOAB to be used as a basis for ESMF grid remapping and related functions. The MOAB mesh migrate code can take an input mesh and a specification of the processor destinations and create a new mesh on those processors. In addition, the MOAB team added options to move variable data stored on the mesh and to delete the original mesh. The ESMF team is using a set of test cases that they developed to validate the new capabilities.

Last year, the ESMF team (Spector) added the MOAB library to the ESMF source code and build process. This year, Bob Oehmke added a switch that can select either MOAB or the original ESMF mesh implementation. Originally the plan was to allow a swap during compile time. However, it was recognized that this would make testing difficult as every capability not yet supported would break. Instead, a runtime method for swapping was chosen, allowing particular tests to be changed to work with MOAB. The next stage is to allow the creation of an ESMF Mesh with a MOAB mesh underneath. During August and July 2014, Bob experimented with MOAB mesh creation and data handling capabilities to prepare for this step. A partial version of this mesh creation capability was implemented in Sept. 2014. The code can successfully create the vertices (i.e. the representations of point locations) of a MOAB mesh from the ESMF specification. The implementation of the code to tie these vertices into the complete mesh has been partially completed, but still needs to be finished. 


\section{Optimize Component Architectures for GPUs}

A set of prototype applications exploring the possibilities of using accelerators with a coupling framework was completed by Jayesh Krishna of ANL and will be reported under the NOPP award An Integration and Evaluation Framework for ESPC Coupled Models. Gerhard Theurich of the ESMF team advised on the ESMF implementation and design strategies.

\section{Couple HYCOM to CESM}

The integration of the HYbrid Coordinate Ocean Model (HYCOM) with the Community Earth System Model (CESM) involves three primary tasks: create a National Unified Operational Prediction Capability (NUOPC) interface or "cap" for the latest HYCOM model (Theurich and others); modify CESM to implement the NUOPC framework (Vertenstein and Edwards); and integrate the HYCOM NUOPC cap (and model) into the NUOPC-CESM system as an alternate ocean model (Saint, Bozec, Liu, and others).

Originally, a NUOPC cap for HYCOM rev37047 was created an integrated into the CESM baseline and was able to run standalone using the NUOPC Driver in CESM. More recently, an updated NUOPC cap for HYCOM rev45185, replaced the original HYCOM in CESM, and now includes the ability to import and export data using Earth System Modeling Framework (ESMF) Fields and Grids.

The integration of the NUOPC framework into CESM is an ongoing process that involves several stages of implementation. Last year, Mariana Vertenstein and Jim Edwards of the CESM team restructured the CESM coupler and driver so that it can accommodate NUOPC components. CESM can now support a NUOPC Driver driving the system, which involves the coupling of all 7 model types (atm, ocn, ice, lnd, rof, glc and wav) with a NUOPC Mediator. While the Mediator provides external interfaces and behavioral rules, it is using the existing coupling code from CESM to implement its internal functionality. CESM handles multiple variations of these component types, with dead, stub, data and active versions. NUOPC Models are used to "cap" these components, and there are currently NUOPC caps for all of the data components (datm, docn, dice, dlnd and drof), 3 of the stub components (slnd, sglc and swav), and 3 of the active components (cice, pop2 and hycom).

An initial test of the NUOPC-CESM version was to run the Parallel Ocean Program (POP2) ocean with the CICE model and ensure that results were the same as in native CESM, which uses the Model Coupling Toolkit (MCT). Fei Liu completed this task, which used NUOPC caps that he had created for the POP2 ocean and CICE ice components. The test configuration was a CESM G compset with POP2 and CICE as active components. The NUOPC version of the model produced bitwise identical results with the native CESM version. A test report of this task is available at https://www.earthsystemcog.org/projects/espc-infrastructure/cice-pop2-test-report-140911

Kathy Saint led the task of HYCOM integration with CESM. An initial step was to ensure that a NUOPC-CESM 1.3 beta04 case that includes HYCOM as the ocean component (instead of POP2) and $\mathrm{CICE}$ as the sea ice component validates in a simple CESM compset $\mathrm{C}$ configuration. This configuration produced bitwise reproducible results with HYCOM running standalone, compared with HYCOM running outside of CESM, see test report: https://www.earthsystemcog.org/projects/espcinfrastructure/hycom_run_test_rpt

The ESMF team is in the process of implementing Field transfers using the NUOPC software, while continuing to use the CESM software to handle the custom coupling code (such as flux calculations). A next critical step is to validate HYCOM running in a CESM compset $\mathrm{G}$ configuration, with active 
HYCOM and CICE. Currently one field, sea_surface_temperature, is being exported from HYCOM in this configuration, and the team is in the process of validating that it is being transferred correctly.

In addition, ESMF team members, Alexandra Bozec and others are going through the list of fields imported to and exported from HYCOM, and determining which of the HYCOM import and export fields correspond to those in the CESM system. We have all of the export fields associated, and 4 import fields remaining.

Additional test reports include:

- All data components using ESMF Fields: https://www.earthsystemcog.org/projects/espcinfrastructure/data_model_fields_test_rpt

- NUOPC POP2 running with other data components: https://www.earthsystemcog.org/projects/espc-infrastructure/pop_only_run_test_rpt

\section{RESULTS}

The major results for this year include the capability to switch between MOAB and the native ESMF finite element mesh, and the ability to partially represent an ESMF mesh object using MOAB. The CESM-HYCOM coupling has resulted in a redesign of the CESM coupling infrastructure to accommodate NUOPC interfaces. Initial configurations using NUOPC-CESM have been validated.

Test reports were written for a NUOPC-CESM configuration with active POP2 ocean and CICE vs the native non-NUOPC version, and a NUOPC-CESM standalone version of HYCOM vs the non-NUOPC version. Current work focuses on validating a coupled configuration of NUOPC-CESM with active HYCOM and CICE. In addition, a set of applications was developed that explore the possibilities of using accelerator technology in the context of a framework for coupled modeling. This work will be summarized under the annual report for the project An Integration and Evaluation Framework for ESPC Coupled Models.

\section{IMPACT/APPLICATIONS}

The results obtained here can be viewed as a head start for the linked proposals funded under the 2013 NOPP AOLI awards. There is a direct correspondence between this preliminary work and the AOLI project An Integration and Evaluation Framework for ESPC Coupled Models (PI: Ben Kirtman). The Kirtman-led project also focuses on a coupled CESM-HYCOM configuration and builds on joint technical work involving NCAR, NRL, DOE laboratories, and ESMF/NUOPC developers.

The work presented here is likely to inform the technical strategies adopted by other NOPP projects as well. For example, streamlining the CESM coupler while introducing NUOPC code is enabling ESMF data structures and methods that support in-memory, during-run grid remapping to be introduced into CESM in an efficient way, preserving existing infrastructure where it makes sense. This capability is likely to be a first step in coupling components with adaptive grids, an objective of the NPS-NRLRice-UIUC NOPP AOLI project. 


\section{RELATED PROJECTS}

The OI for ESPC project is most closely related to the projects supported under the 2013 NOPP AOLI awards, listed on this page: http://coaps.fsu.edu/aoli/projects

The current work is particularly relevant to the AOLI project An Integration and Evaluation Framework for ESPC Coupled Models (PI: Ben Kirtman), which also focuses on a CESM-HYCOM configuration and includes joint technical work involving NCAR, DOE laboratories, and ESMF/NUOPC developers.

\section{REFERENCES}

AOLI: http://coaps.fsu.edu/aoli

CESM: http://www2.cesm.ucar.edu/

CoG: http://earthsystemcog.org/

ESMF: http://www.earthsystemmodeling.org/

HYCOM: http://hycom.org/

MCT: http://www.mcs.anl.gov/research/projects/mct/

MOAB: https://trac.mcs.anl.gov/projects/ITAPS/wiki/MOAB

NUOPC Layer: http://earthsystemcog.org/projects/nuopc/ 